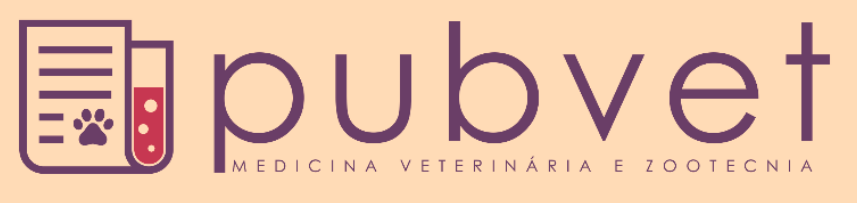

https://doi.org/10.31533/pubvet.v15n06a829.1-11

\title{
Coronavírus bovino: Revisão
}

Urias Fagner Santos Nascimento ${ }^{\bullet} 1 *$, Elizabete de Oliveira Lopes Melo ${ }^{\circ}$, Vitoria Lorena de Matos Santana ${ }^{\circ}$, Ana Paula Alves Melo ${ }^{2}$, Yuri Rafael Teixeira de Souza Correia ${ }^{\circ}$, João Vitor Oliveira Bomfim ${ }^{\bullet}$, Ana Carolina Trompieri Silveira Pereira ${ }^{\bullet}$, Gabriel Isaías Lee Tuñón ${ }^{\circ}$ (D) ${ }^{3}$, Huber Rizzo ${ }^{\circ}$

${ }^{1}$ Doutorando em Ciência Veterinária, Universidade Federal Rural de Pernambuco, Campus Dois Irmãos - Recife, Pernambuco, Brasil. ${ }^{2}$ Discentes do curso de Medicina Veterinária, Universidade Federal de Sergipe, Campus São Cristóvão, Sergipe.

${ }^{3}$ Docente do Departamento de Medicina Veterinária, Universidade Federal de Sergipe, Campus São Cristóvão, Sergipe.

${ }^{4}$ Docente do Departamento de Medicina Veterinária, Universidade Federal Rural de Pernambuco, Campus Dois Irmãos - Recife, Pernambuco, Brasil. *Autor Para correspondência, E-mail: uriasfagner@hotmail.com

Resumo. O Coronavírus bovino (BCoV) faz parte da família Coronaviridae e possui uma cadeia simples de RNA envelopado, podendo ter quatro ou cinco proteínas (M, Sm, He, S e I) que se projetam em uma dupla camada de lipídeos. Além das infecções entéricas relacionadas ao $\mathrm{BCoV}$ há também indícios de que ele seja agente de processos respiratórios as quais podem ser fatais em bovinos adultos. Inicialmente ele se replica causando infecções gastrointestinais e posteriormente afeta as os cornetos nasais, traqueia e pulmão. A transmissão do $\mathrm{BCoV}$ é horizontal direta, a partir de alimentos ou água contaminada com as fezes ou secreção respiratória contendo o vírus. Seu período de incubação é de três a sete dias, até aparecerem os sinais clínicos de diarreia, porém antes do surgimento dos novos sinais o animal já pode eliminar o vírus em grande quantidade em suas excreções. $O$ diagnóstico pode ser através de ELISA, microscopia eletrônica, cultura viral, PCR e ensaio de hemaglutinação. A profilaxia das infecções por BCoV está relacionada a adoção de práticas corretas de manejo, além, da vacinação em bezerros e animais adultos. Constatouse no presente trabalho que o coronavírus bovino (BCov) é o agente etiológico responsável por agir e/ou agravar infecções associadas a diarreia e doenças respiratórias em bovinos de todas as idades, sendo um vírus extremamente contagioso, que afeta a sanidade do rebanho e o setor econômico mundial por sua alta morbidade e significante de mortalidade entre os bezerros.

Palavras-chave: $\mathrm{BCoV}$, diarreia, síndrome respiratória, bovinos

\section{Bovine coronavirus: Review}

Abstract. Bovine Coronavirus (BCoV) is part of the Coronaviridae family. This virus belongs to a simple enveloped RNA chain that has 4 or 5 proteins (M, Sm, He, S and I), they project on a double layer of lipids. In addition to enteric infections related to $\mathrm{BCoV}$ (diarrhea in neonates and winter dysentery) there is also evidence that it is an agent of respiratory syndromes which can be fatal in adult cattle. Thus, studies show that initially it replicates causing gastrointestinal infections and later affects the nasal turbinates, trachea and lung. (Pavarini, 2009). There are some ways to detect bovine coronavirus, as already mentioned, the use of ELISA, electron microscopy, viral culture, PCR, hemagglutination assay. $\mathrm{BCoV}$ transmission is a direct horizontal transmission, when the animal comes into contact with the virus from food or water contaminated with the feces or respiratory secretion of the infected animal. The incubation period is 3 to 7 days, to show clinical signs such as diarrhea in animals, but before the appearance of new clinical signs, the animal can already eliminate the virus in large quantities. The prophylaxis of Coronavirus infections 
is related to the adoption of correct management practices, in addition, several types of vaccines have been developed to protect herds, with application in calves and adult animals. It was found in the present study that bovine coronavirus (BCov) is the etiological agent responsible for acting and / or aggravating infections associated with diarrhea and respiratory diseases in cattle of all ages, etiology and pathology not very precise, being an extremely contagious virus, which affects the health of the herd and the world economic sector in order to have a significant mortality rate among calves, and a high morbidity.

Keywords: $\mathrm{BCoV}$, diarrhea, respiratory syndrome, bovine, ruminants

\section{Coronavírus bovino: Revisión}

Resumen. El Coronavirus Bovino (BCoV) hace parte de la familia Coronaviridae y posee una cadena simple de RNA envuelto que puede tener cuatro o cinco proteínas (M, Sm, He e I) y se proyectan en una camada doble de lípidos. Además de las infecciones entéricas relacionadas al $\mathrm{BCoV}$ hay también pruebas de que sea un agente de procesos respiratorios los cuales pueden ser fatales en bovinos adultos. Inicialmente este virus se replica causando una infección gastrointestinal, que luego afecta los cornetes nasales, tráquea y pulmones. La transmisión del $\mathrm{BCoV}$ es horizontal, a partir de alimentos o agua contaminada con las heces o secreciones respiratorias que contengan el virus. Su periodo de incubación es de tres a siete días, hasta aparecer signos clínicos como diarrea, sin embargo, antes de estos nuevos síntomas, el animal ya puede eliminar el virus en grandes cantidades en sus excreciones corporales (excrementos y secreciones nasales). El diagnostico puede ser a través de ELISA, microscopia electrónica, cultivo viral, PCR y ensayo de hemaglutinación. La profilaxis de las infecciones por $\mathrm{BCoV}$ está relacionada a la correcta practica de manejo del rebaño, además de las vacunaciones de los terneros y los animales adultos. En el presente trabajo se pudo verificar que el $\mathrm{BCoV}$ es un agente etiológico responsable por afectar y empeorar infecciones asociadas a la diarrea y enfermedades respiratorias en bovinos de todas las edades, siendo un virus altamente contagioso, que afecta la sanidad del rebaño y el sector económico mundial por su alta morbilidad y significante mortalidad en los terneros.

Palabras clave: $\mathrm{BCoV}$, diarrea, síndrome respiratorio, bovinos

\section{Introdução}

O Brasil é o país que detém o maior rebanho comercial bovino do mundo, sendo o principal produtor e exportador de carne (FAPRI, 2020). No entanto, quando se tem um grande rebanho é comum que várias doenças possam surgir, muitas vezes decorrentes da concentração de indivíduos. Dentre essas enfermidades, destacam-se as doenças infecciosas que possuem fácil disseminação e podem levar a grandes perdas econômicas, uma vez que o seu tratamento se torna dispendioso e muitas vezes ineficiente, o que leva a morte dos animais ou ao baixo desenvolvimento produtivo. Dentre os agentes causadores de doenças infeccionas nos bovinos, destaca-se o Coronavírus bovino (BCoV) (Barry et al., 2009; Reck, 2009; Lorenzetti et al., 2013; Oliveira, 2018).

Os primeiros relatos sobre o vírus, o apontam como responsável pela diarreia neonatal em bezerros nos Estados Unidos da América (EUA), no ano de 1972. Nesse mesmo período iniciou-se o estudo de suas caracteristicas morfológicas, que permitiram a sua inclusão no grupo dos coronavírus (Betancourt et al., 2006; Sonza, 2006; Takiuchi et al., 2007; Souza, de et al., 2010; Júnior, 2015).

O BCoV faz parte da família Coronaviridae, ordem Nidovirais, gênero Coronavírus e espécie Betacoronavírus-1 (Kanno et al., 2018; Szczepanski et al., 2019), são vírus de RNA fita simples não segmentados, com um sentido positivo e envelopado com dupla camada de lipídeos (Pavarini, 2009; Fulton et al., 2015; Bok et al., 2018; Kanno et al., 2018).

Estudos afirmam a possibilidade de animais assintomáticos eliminarem o $\mathrm{BCoV}$ nas fezes, tornandose reservatórios e transmissores da doença, o que dificulta o seu controle, possibilitando o surgimento 
de novos surtos, já que o vírus continua a infectar os animais recém-chegados ao rebanho ou imunossuprimidos (Pavarini, 2009).

A transmissão do $\mathrm{BCoV}$ é horizontal direta, quando o animal entra em contato com o vírus a partir de alimentos ou água contaminada com as fezes ou secreções respiratórias. O período de incubação do é de três a sete dias, até os sinais clínicos de diarreia, porém antes do surgimento dos novos sinais o animal já pode eliminar o vírus em grande quantidade (Pavarini, 2009; Gomez et al., 2017; Kanno et al., 2018). O diagnóstico do BCoV pode ser realizado através de uma cultura viral, PCR, ensaio de hemaglutinação usando eritrócitos de camundongo além de ELISA de captura de antígenos (Gomez et al., 2017).

Assim, este trabalho tem como objetivo fazer uma revisão de literatura acerca do $\mathrm{BCoV}$ e suas implicações na saúde dos rebanhos bovinos.

\section{Etiologia}

O coronavírus bovino pertence a ordem dos Nidovirales, da família Coronaviridae e ao gênero Coronavírus, o seu RNA é não segmentado com polaridade positiva. Esse gênero está dividido em três grupos (Grupo I, Grupo II, Grupo III), de conformidade dos etípotos presentes nas glicoproteínas de envelope, a sequência de nucleotídeos, além da predileção por hospedeiros naturais, desses grupos o BCoV está incluso no Grupo II, que compreende também o Coronavírus Respiratório Humano C43, Vírus da Hepatite Murina, além do Vírus Encefalomielite Hemaglutinante Suína e o Vírus Sialodacrioadenite (Betancourt et al., 2006). Esse vírus possui uma cadeia simples de RNA envelopado que detém quatro ou cinco proteínas (M, Sm, He, S e I), que se projetam em dupla camada de lipídeos e conferem a partícula viral o aspecto de coroa, devido a isso o nome coronavírus, sendo a proteína " $\mathrm{S}$ " a mais importante, com 1.363 aminoácidos, uma vez que é responsável pela forma espiculada da partícula do vírus, atividade hemoaglutinante, adesão aos receptores das células dos hospedeiros, além de ser o principal local de ligação para anticorpos neutralizantes e considerada a proteína mais polimórfica dos coronavírus (Sonza, 2006; Pavarini, 2009; Fulton et al., 2015).

Ademais a proteína M (matriz) tem 221 a 262 aminoácidos, possui função na montagem da partícula viral, já que forma a estrutura do envelope. Já a proteína Sm ("Small membrane protein") é composta de 84 a 109 aminoácidos e também é essencial na estrutura do envelope. A proteína HE (Hemaglutininaesterase) é acessória exclusiva do grupo II, possui a forma de dímero e age como um cofator da proteína $\mathrm{S}$, possuindo atividade de enzima destruidora de receptores (esterase). Possui morfologia predominantemente esférica, com diâmetro de aproximadamente $100-150 \mathrm{~nm}$, o capsídeo apresenta simetria helicoidal com predomínio de fosfoproteína $\mathrm{N}$ (nucleocapsídeo), envolvendo o genoma viral. A proteína não estrutural mais importante dos coronavírus é a RNA-replicase, que é responsável pela transcrição e pela replicação viral (Sonza, 2006; Pavarini, 2009; Fulton et al., 2015).

Os Coronavírus são agentes pouco resistentes a condições ambientais ou a maioria dos desinfetantes utilizados na pecuária sendo facilmente inativado por detergentes e com solvente orgânicos, devido a presença de lipídeos no seu envelope viral. Ele também possui uma sobrevivência baixa na natureza, em temperatura ambiente. São vírus sensíveis a temperaturas elevadas e radiação solar (Betancourt et al., 2006).

\section{Reprodução viral}

Para que haja a infecção da célula hospedeira, é preciso que a proteína HE viral se ligue ao ácido 90 -acetil neuroamaina, encontrado em grande quantidade nas macromoléculas presentes na membrana celular. Estudos de inibição da proteína viral HE, levaram a inibição da infecção viral, porém não houve um bloqueio total da infecção (Betancourt et al., 2006). Após a ligação com seu receptor especifico, o vírus adentra a célula em um processo dependente da proteína $S$, que é responsável pala união do envelope viral e a membrana celular (Letko et al., 2020).

O ácido nucleico do vírus atua como RNA mensageiro e é traduzido em uma poliproteína, que é processada co e pós-traducionalmente, precursora da polimerase e outras proteínas virais que participam da síntese do RNA viral. A polimerase utiliza produtos do RNA genômico como modelo para produção do RNA sub-genômico de sentido negativo. Esse é utilizado para sintetizar RNA genômico e mRNA 
sub-genômico, ambos com polaridade positiva. Cada um dos mRNAs são traduzidos em uma única proteína incluindo as estruturais e não-estruturais (Betancourt et al., 2006).

Com a formação do RNA genômico da progênie viral e formação dos novos vírus, no reticulo endoplasmático e no complexo de Golgi, encerra-se o processo de reprodução viral e os novos indivíduos são liberados da célula por transporte vesicular ou por exocitose (Fehr \& Perlman, 2015).

\section{Hospedeiros}

As coronaviroses acometem bovinos e ruminantes selvagens, com infecções respiratórias e entéricas. Possíveis reservatórios de coronavírus bovino de vida selvagem foram identificados, como veados sambar, gazela de cauda branca, waterbuck, alce e girafas que abrigam coronavírus que estão relacionados biologicamente, antigenicamente e geneticamente com o $\mathrm{BCoV}$, além de búfalos e alpacas onde foram identificados coronavírus semelhante aos bovinos (Saif, 2010). Bovinos adultos com a doença subclínica podem ser reservatórios do $\mathrm{BCoV}$, assim como alguns ruminantes selvagens que vivem em cativeiro e na vida livre. Além disso, há relatos de transmissão acidental do BCoV a humano (Pavarini, 2009).

\section{Patogenia}

O entendimento da patogênese do coronavírus bovino ainda é pouco desenvolvido entre os pesquisadores. Dados observados são, necessariamente, retirados das dissecações das proteínas estruturais e dos genes que a codificam e de infecções em bezerros infectados experimentalmente pelo $\mathrm{BCoV}$ por amostras de disenteria de inverno. No entanto, as lesões são menos evidentes ao realizar necropsia 24 a 48 horas após inoculação, pois a mucosa do trato gastrointestinal passa a reagir com o leite coagulado (Betancourt et al., 2006; Pavarini, 2009).

Além das infecções entéricas relacionadas ao $\mathrm{BCoV}$ há também indícios de que ele seja agente de síndromes respiratórias, abrangendo inclusive o complexo de doença respiratória bovina (CDRB) em bovinos confinados, sendo comum levar o animal a estado de broncopneumonia. A infecção pode influenciar negativamente no ganho de peso do animal, acometendo o desempenho e saúde do rebanho. Inicialmente o vírus se replica causando lesões gastrointestinais, seguida de inflamação nos cornetos nasais e traqueia. É encontrado no pulmão e em secreções nasais, e está associado a um quadro agudo de pneumonia intersticial em bezerros (Pavarini, 2009; $\underline{\text { Saif, 2010). }}$.

$\mathrm{O}$ vírus acomete células do intestino delgado e grosso, causando necrose e a substituição por células imaturas. A diarreia se dá devido a uma fusão na vilosidade do intestino delgado causado pelo BCoV, atrofia das criptas do cólon no intestino grosso onde há degeneração resultando em descamação. As criptas se apresentam dilatadas, podendo apresentar coágulos de sangue, com necrose do epitélio de revestimento (Figura 1). É também observado linfonodos mesentéricos aumentados em bezerros, além de lesões decorrentes de infecções concomitantes não relacionadas (Pavarini, 2009; Júnior, 2015).

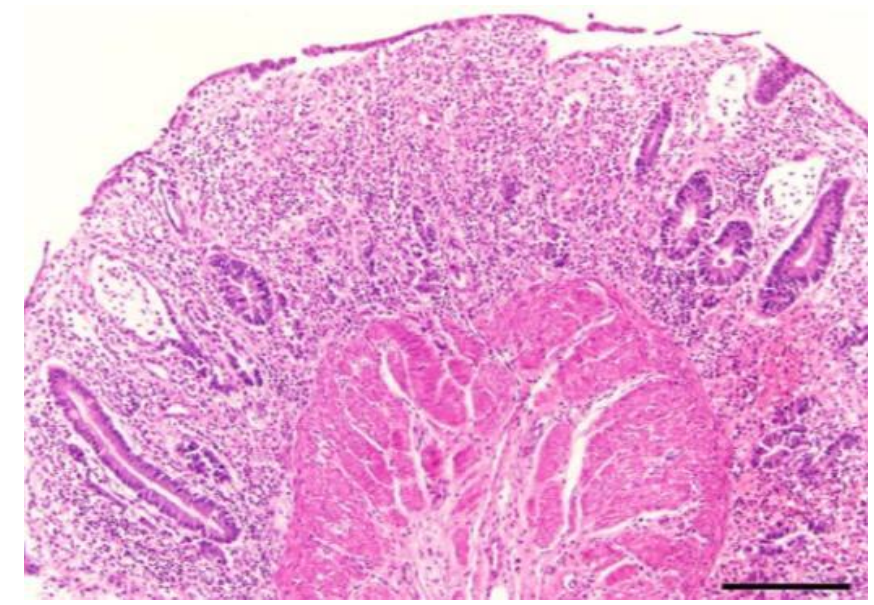

Figura 1. Cólon bovino. Colite linfoplasmocítica com necrose e perda de cripta regionalmente extensa, reepitelização e hemorragia. Coloração: H\&E. Fonte: Fulton (2015). 
A absorção do intestino é reduzida com a junção das células imaturas somadas as perdas de áreas absortivas, porém há células que mantêm as atividades secretoras, dessa forma ocorre aumento de líquido na luz intestinal, provocando a diarreia. A lactose advinda do leite ingerido pelo bezerro, não totalmente coagulada no abomaso, não é digerida, uma vez que não existe liberação das enzimas que realizam essa função e as células que são responsáveis por essa liberação se acumulam no lúmen intestinal, aumentado assim a atividade microbiana e causando um desequilíbrio osmótico. Esse atrai mais água, ocasionando a perda eritrócitos e água, chegando em casos graves, a ocorrência de acidose, hipoglicemia e desidratação (Júnior, 2015).

$\mathrm{O}$ trato respiratório é acometido na parte superior da cavidade nasal, traqueia e ocasiona bronquiolite e alveolite, congestão e hemorragias, e pode espalhar-se para regiões próximas causando inflamação. Quando atua no CDRB o vírus tem participação em lesões pulmonares que podem evoluir para pneumonia lobar exsativa e necrosante fibrinosa, além de reduzir a imunidade do hospedeiro aumentando o risco de coinfecções bacterianas virais e secundárias (Betancourt, 2006; Saif, 2010).

Estudos realizados em Ontario, Canadá, entre 2008 e 2012 mostram uma prevalência de 3,4 a 40\% de $\mathrm{BCoV}$ em bezerros diarreicos e 7,4\% em bezerros saudáveis. Esse estudo indica crescimento no índice de contaminação dos animais em relação a anos anteriores, evidencias mostram que em 1982 existia uma prevalência de $17 \%$ de $\mathrm{BCoV}$ diarreicos, e em 1988 de 13\% para o mesmo grupo e 2,3\% entre os saudáveis. Esse aumento está associado a práticas de manejo realizadas atualmente, com aumento na densidade demográfica nos bezerreiros facilitando a contaminação, o uso de drogas antimicrobianas, diferença nos testes de detecção de $\mathrm{BCoV}$ além do surgimento de novas cepas no decorrer dos anos (Gomez et al., 2017).

\section{Prevalência}

Dados de prevalência são variáveis quando se observa diferentes regiões ao redor do mundo. No Brasil, ainda são poucos os trabalhos que tratam da prevalência das coronaviroses em bovinos, estes dados encontram-se compilados na Tabela 1.

Tabela 1. Levantamentos de ocorrência de Coronavírus bovino em bovinos segundo país, região, categoria animal, teste diagnóstico utilizado, prevalência e autores.

\begin{tabular}{lccccc}
\hline País & Região & Categoria & Teste Diagnóstico & Prevalência & Autores \\
\hline \multirow{4}{*}{ Brasil } & RO & Bezerros & SN-PCR & $14,3 \%(3 / 21)$ & (Lorenzetti et al., 2013) \\
& MS & Bezerros & SN-PCR & $48,1 \%(13 / 27)$ & (Lorenzetti et al., 2013) \\
& MG & Bezerros & SN-PCR & $34,8 \%(8 / 23)$ & (Lorenzetti et al., 2013) \\
& SP & Bezerros & Hemaglutinação & $39 \%(26 / 72)$ & (Jerez et al., 2002) \\
Canadá & PR & Bezerros & PCR & $42,4 \%(14 / 33)$ & (Mello et al., 2016) \\
China & Ontário & Bezerros & RT-PCR & $55 \%(157 / 286)$ & (Gomez et al., 2017) \\
Índia & Gansu & Bezerros & RT-PCR & $18,9 \%(36 / 190)$ & (Geng et al., 2019) \\
Irã & Mathura & Bezerros & Elisa & $4,76 \%(3 / 63)$ & (Dash et al., 2012) \\
& Fars & Bezerros & Elisa & $11,3 \%(32 / 287)$ & (Badiei et al., 2012) \\
\hline
\end{tabular}

\section{Sinais clínicos}

O coronavírus bovino pode desenvolver três síndromes: disenteria do inverno, diarreia neonatal e síndrome respiratória (Betancourt et al., 2006).

\section{Disenteria de inverno}

A disenteria de inverno (Winter Disentery-DW) é uma importante doença infectocontagiosa, com padrão sazonal e tendência mundial, que atinge o gado adulto em estações frias do ano e com maior prevalência em vacas leiteiras maduras (Yavru et al., 2016). Estudos menos recentes apontam a associação da disenteria com diversos agentes tais como o rotavírus, Vírus da Diarreia Viral Bovina (BVD), enterovírus (WD-42) e Camplylobacter (Vibrio). Mas, atualmente diversos trabalhos indicam que o $\mathrm{BCoV}$ vem sendo agente primário da doença, uma vez que é encontrado nas fezes de animais 
enfermos durante os surtos, além de pesquisas que demonstram a presença do vírus em lesões intestinais (Brandão et al., 2007). No Brasil, o primeiro caso da doença foi descrito no estado de São Paulo em 2001, em fazenda de gado leiteiro, e posteriormente em Minas Gerais (Souza, 2008).

A síndrome clínica apresenta alta taxa de morbidade, embora baixa mortalidade entre os bovinos adultos, levando a disenteria aguda severa, por vezes com presença de muco e/ou sangue (Figura 2), fezes liquidas esverdeadas contendo estrias de sangue, e/ou marrom-escuras, com intensa excreção de material entérico, graus variáveis de depressão, cólicas leves, anorexia, perda de apetite, corrimento nasolacrimal mucoso com estrias de fibrinas e tosse. Sistemicamente ocorre perda de peso, e consequente redução do condição corporal, e desidratação levando a queda súbita da produção de leite em até $90 \%$ (Souza, 2008). Frequentemente ocorre a recuperação espontânea dos animais em poucos dias, no entanto a produção não costuma voltar aos níveis anteriores durantes vários meses (Bezerra et al., 2009).

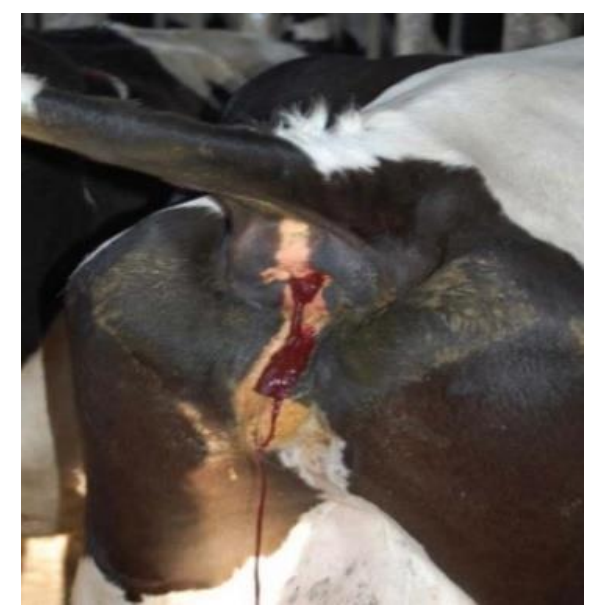

Figura 2. Diarreia sanguinolenta em bovino leiteiro. Fonte: Pavarini (2009).

\section{Diarreia neonatal}

Essa síndrome é caracterizada por diarreia líquida abundante, podendo haver vestígios de sangue nas fezes, ocasionado pela hemorragia intestinal, desidratação (Figura 3), evoluindo a hipovolemia em poucas horas após o início dos sinais clínicos, resultando na morte do animal (Betancourt et al., 2006). Em bezerros, principalmente na faixa etária de até trinta dias, é uma das síndromes mais frequente e importantes enfrentadas pelos médicos veterinários buiatras, uma vez que é uma das principais causas de mortalidade de bezerros no mundo, e resultado da relação de vários fatores como manejo, nutrição, ambiente. Essa doença, causa prejuízos financeiros tanto aos proprietários de gado de leite, com a diminuição na produção, quanto ao de corte, uma vez que interfere no tempo de ganho de peso do animal e consequentemente no escore corporal, assim o animal tem que permanecer por mais dias na propriedade para chegar no peso ideal de abate. Além disso, há gastos com tratamentos e a possível morte do animal, pois a mortalidade estimada em bezerros devido diarreias chegue a mais de $50 \%$ (Jerez et al., 2002; Barry et al., 2009; Lorenzetti et al., 2013).
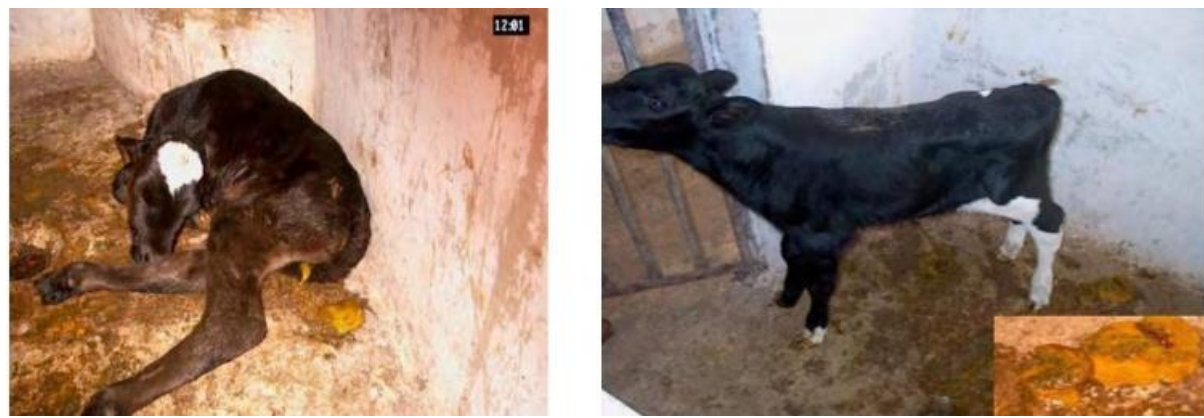

Figura 3. Bezerros apresentando diarreia amarelada com presença de coágulos, decorrente de infecção por BCoV. Fonte: Betancourt (2006). 
Normalmente a diarreia neonatal é ocasionada por uma coinfecção entre rotavírus e coronavírus bovino, com os dois atingindo a mesma porção do intestino delgado. No entanto, ainda não se sabe bem como ocorre a infecção, uma vez que não é conhecida a relação entre esses dois vírus, se de comensalismo, competição ou ainda como se sugere, sinergismo (Barry et al., 2009). Estudos brasileiros afirmam que o $\mathrm{BCoV}$ obteve maior prevalência do que o rotavírus bovino nas fezes de animais diarreicos, com $16 \%$ e $11 \%$ respectivamente (Júnior, 2015).

No Brasil, relatos de infecção por $\mathrm{BCoV}$ em rebanhos bovinos de corte criados extensivamente não são frequentes, sendo considerado incomum a diarreia neonatal em bezerros criados no sistema extensivo, mas recentes estudos relatam aumento da intensidade na circulação do vírus nos rebanhos nacionais. Recentemente foram adotadas praticas para aumento da eficiência na produção, com a adoção de novas técnicas de manejo, aumentando os fatores de risco de infecção, além de fatores como concentração de animais jovens, mais propícios a infecções, desmame precoce e mistura de bezerros de várias idades e diferentes estágios imunológicos, aumentando os risco da doença (Lorenzetti et al., 2013).

\section{Síndrome respiratória}

O BCoV é também autor de infecções respiratórias em bovinos de todas as idades, sendo identificado em amostras de animais convalescentes devido pneumonia, a partir de amostras de fezes, secreções nasais e em pulmões. Sua transmissão assemelha-se com as demais síndromes sendo predominante a forma respiratória (aerossóis) (Asano et al., 2009; Saif, 2010).

No Brasil, não foram encontrados muitos relatos de detecção do $\mathrm{BCoV}$ como agente de processos respiratórios, mas trabalhos realizados na Noruega, Itália e EUA seguem atribuindo o vírus como principal agente (Saif, 2010). O primeiro relato da detecção do vírus em secreções nasais em bezerros com doenças respiratórias no país, ocorreu no estado do Paraná (Mello et al., 2016).

A síndrome respiratória ocorre em animais com sistema imune debilitado, bezerros que não receberam colostro e pode ser fatal em bovinos de idade avançada, uma vez que combinada a outros fatores como coinfecções advindas de outros microrganismos e estresse acentuam o agravamento da doença. Há pesquisas que visam comparar a diversidade dos sintomas das três síndromes clínicas relatando a ação do vírus no trato respiratório de bezerros, especialmente os que não ingerem colostro após o nascimento. Estes animais tem maior chance de desenvolvimento do quadro clinico, especialmente no período entre seis e dez meses de vida (Betancourt et al., 2006; Mello, 2018).

Os sintomas clínicos podem variar de gravidade e envolve principalmente tosse, febre de remessa, perda de apetite, traqueíte, descarga nasal serosa a mucopurulenta, diarreia e está altamente relacionado com pneumonia em bezerros jovens, com duração de uma a duas semanas. A redução no ganho de peso está altamente relacionado a esta síndrome, afetando desempenho, produção e saúde do mesmo (Saif, 2010; Geng et al., 2019).

A febre de transporte, uma das faces do CDRB, é uma importante doença que causa mortalidade em bovinos de corte, principalmente nos EUA, respondendo por cerca de $75 \%$ da morbidade e $50 \%$ das mortes (Serafini, 2016, Headley et al., 2017). Estudos sugerem que o BCoV acentua a gravidade da doença respiratória em bezerros confinados, ou seja, o vírus pode atuar como infecção subjacente, uma vez que os pesquisadores encontraram derramamento nasal e fecal pelo $\mathrm{BCoV}$ em animais recém chegados aos confinamentos e que depois progrediu para o CDRB, ocasionando pneumonia e morte do gado. Fatores predisponentes para o vírus atuar dessa forma são as longas distâncias que causam estresse no hospedeiro, seguido de imunossupressão. Os animais sintomáticos apresentaram febre alta e dificuldade para respirar grave, e implicou caso de pneumonia em bezerros até seis meses de idade (Saif, 2010).

\section{Diagnóstico}

Para realização do diagnóstico conclusivo do $\mathrm{BCoV}$ é necessário o seu isolamento em amostras clínicas de animais suspeitos, porém torna-se difícil, uma vez que a eliminação viral limita-se entre três a seis dias, além da ocorrência de casos subclínicos (Mello, 2018). 
O diagnóstico laboratorial é realizado através da coleta de amostra de fezes direto da ampola retal do animal, principalmente com quadro de diarreia ou desinteira, a partir do primeiro ao quarto dia de sintomas, ou amostra de secreção nasal sendo importante mantê-las acondicionada em vasos estéreis e transportadas em geladeiras virológicas com gelo. Para a pesquisa da soroconversão, a amostra de sangue deve ser coletada no momento da infecção e cerca de catorze dias depois após a mesma, em frasco sem anticoagulante e centrifugada para a obtenção do ou soro. É importante que a coleta seja realizada de forma adequada e o armazenado correto para não comprometer o diagnóstico (Betancourt et al., 2006). Dentre as técnicas diagnósticas utilizadas para auxiliar ou diagnosticar a presença do agente estão:

Ensaio de Imunoabsorção Enzimática (ELISA): permite a detecção de anticorpos anti-BCoV, com a vantagem de ser aplicável em um grande número de amostras de soro, porém mostrou-se menos sensível que a imunomicroscopia eletrônica para detecção do coronavírus bovino em diarreia de inverno (Pavarini, 2009).

Reação em Cadeia da Polimerase (PCR): é de alta especificidade e sensibilidade na detecção de pequenas quantidades de ácidos nucleicos de coronavírus, no início ou no final da infecção, quando os animais podem apresentar baixa eliminação viral, evitando assim resultados falso negativo (Pavarini, 2009; Mello, 2018).

Cultura viral: o isolamento do vírus é um teste muito sensível e permite a caracterização genômica e antigênica de isolados selvagens, porém é demorado e dispendioso (Mello, 2018).

Microscopia eletrônica: o diagnóstico laboratorial para o coronavírus iniciou-se com essa técnica, porém requer um longo período para o processamento das amostras e o seu custo de implementação é muito alto (Sonza, 2006).

Ensaio de Hemaglutinação (HA): o uso da HA dos eritrócitos de hamster de amostras de fezes, seguido de inibição de hemaglutinação (IHA) e ELISA foram descritos provando ser métodos rápidos para a detecção do coronavírus bovino, adequados para ensaio de larga escala e fáceis de manusear, sendo no ELISA onde os melhores resultados são obtidos, apesar do RT-PCR ser mais sensível para detecção de baixas concentrações do BCoV (Betancourt et al., 2006). Os testes de hemaglutinação são afetados pelas aglutininas inespecíficas presente nas fezes (Dash et al., 2012).

Histopatologia: os achados histopatológicos mais comuns são observados no cólon espiral com as criptas dilatadas, apresentando necrose do epitélio de revestimento e inúmeras células degeneradas com núcleo em picnose, cariorrexe, degeneração hidrópica e gota hialina. Pavarini (2009) observou infiltrado inflamatório na lâmina própria junto a um grande número de leucócitos, macrófagos, plasmócitos e eosinófilos. O material de eleição para o diagnóstico post-mortem de $\mathrm{BCoV}$ são fragmentos do trato respiratório superior e pulmões, porção final do intestino delgado e do cólon ( $\underline{\text { Saif, 2010; }}$ Lorenzetti et al., 2013)

Em achados de necropsia de animais com desenvolvimento da diarreia neonatal as células do epitélio do intestino delgado e do colón deixam sua forma original para serem cuboides, as células vizinhas se fundem e consequentemente há profunda destruição do epitélio e da cripta. Os bezerros se encontram desidratados e com distúrbios circulatórios (Betancourt et al., 2006; Floss et al., 2019). Na disenteria de inverno as lesões são mais evidentes microscopicamente no cólon, onde há profunda degeneração e possibilidade de coágulos de sangue e na mucosa, e é encontrado hemorragia petequial com frequência, além de diferentes graus de flacidez e dilatação com líquido escuro geralmente misturado com muco e sangue no intestino delgado. No trato respiratório superior é evidente hemorragia petequial (Betancourt et al., 2006; Pavarini, 2009).

\section{Prognóstico}

O prognóstico da doença no início do surto é reservado devido sua alta taxa de morbidade, no entanto sua mortalidade é baixa ou nula. O prognóstico é desfavorável em casos de bezerros que não consumiram colostro adequado, rebanho que apresentam situações críticas de manejo, ambiente/fatores que causem stress e alteração no organismo que leve a baixa imunidade do hospedeiro (Souza, 2008; Bezerra et al., 2009). 


\section{Tratamentos}

Os animais com BCoV devem permanecer em isolamento (Oliveira, 2018). O tratamento não é específico e segue a terapia para ECET, porém não se deve realizar a prática de hidratação oral, uma vez que com a lesão celular intestinal não ocorrerá a absorção. É importante realizar o monitoramento do animal, terapia de hidratação, inicialmente endovenosa, e antibioticoterapia para infecções secundárias (Radostits et al., 2010; Reck, 2009). A medida que o bezerro se recupera, a reidratação e alimentação poderão voltar a ser realizada via oral (Oliveira, 2018), sendo que o tratamento sintomático tem sido o mais recomendado. No entanto, os animais apresentam dificuldade de retomar os índices produtivos anteriores ao quadro da doença (Radostits et al., 2010; Reck, 2009). É relatado que o bezerro pode voltar a se recuperar espontaneamente dentro de três dias, o que torna o tratamento duvidoso (Pavarini, 2009).

\section{Profilaxia}

A profilaxia das infecções por $\mathrm{BCoV}$ está relacionada a adoção de corretas práticas de manejo, sendo imprescindível uma boa nutrição e higiene das instalações, garantindo ambientes limpos e secos, sem contato entre diferentes rebanhos, e garantindo que os animais recém adquiridos passem por quarentena antes de serem introduzidos (Oliveira, 2018).

Além disso, diversos tipos de vacinas foram desenvolvidas para proteger os rebanhos, com aplicação em bezerros e animais adultos, que proporcionam a proteção adequada do animal (Betancourt et al., 2006). As vacas secas devem ser vacinadas de três a seis semanas antes do parto com rota-coronavírus inativado, com reforço quarto semanas antes do parto (Reck, 2009). As vacinas contra diarreia de bezerro possuem cepas de rotavírus bovino e de $\mathrm{BCoV}$ inativadas, os bezerros ficam protegidos de vírus e de algumas bactérias que normalmente são inclusas na vacina (Barry et al., 2009).

No Brasil, existem vacinas comerciais que conferem boa imunidade tanto para as vacas gestantes, que irão transmitir aos bezerros via colostro, como para a vacinação de bezerros (Silva et al., 2008; Souza et al., 2009).

\section{Considerações finais}

Constatou-se no presente trabalho que o coronavírus bovino $(\mathrm{BCoV})$ é o agente etiológico responsável por agir e/ou agravar infecções associadas a diarreia e doenças respiratórias em bovinos de todas as idades, com etiologia e patogenia pouco precisa, sendo um vírus extremamente contagioso. Foi observado principalmente a relação do vírus com três importantes síndromes (diarreia neonatal, disenteria de inverno e a síndrome respiratória) que afetam a sanidade do rebanho e o setor econômico mundial, devido sua alta morbidade e significante taxa de mortalidade entre os bezerros, visto que medidas de controle, profilaxia e tratamento não tendem a ser exatas, até então. No entanto, vale ressaltar a importância de minimizar a exposição dos animais a quaisquer patógenos e evitar que os mesmos sejam negligenciados, de modo a controlar e monitorar a criação. No mais, promover um ambiente adequado de manejo, limpo e seco, assegurar a colostragem e evitar fatores externos estressantes.

\section{Referênciass}

Asano, K. M., Souza, S. P., Silva, S. O. S., Richtzenhain, L. J., \& Brandão, P. E. (2009). Rapid detection of bovine coronavirus by a semi-nested, RT-PCR. Pesquisa Veterinaria Brasileira, 29(11), 874-880. DOI: https://doi.org/10.1590/s0100-736x2009001100001

Badiei, K., Pourjafa, M., \& Ghane, M. (2012). Revista Turca de Ciências Veterinárias e Animais Detecção de antígeno do coronavírus fecal em bezerros diarréicos de alta e média produção infecção nas 4 localizações geográficas diferentes ( norte, oeste, leste e oeste ) dos bezerros diarreicos HPDC e. Revista Turca de Ciências Veterinárias e Animais, 296-302.

Barry, A. F., Alfieri, A. F., Stipp, D. T., \& Alfieri, A. A. (2009). Bovine coronavirus detection in a collection of diarrheic stool samples positive for group a bovine rotavirus. Brazilian Archives of Biology and Technology, 52, 45-49. DOI: https://doi.org/10.1590/s1516-89132009000700006

Betancourt, A. M., Rodriguez, E. B., \& Barrera, M. V. (2006). Coronavírus bovino: infecções 
pneumumoentéricas. Revista Veterinaria Eletronica REDVET, 7, 1-28.

Bezerra, J. S., Brandão, P. E., Pavarini, S. P., Varaschin, M. S., Wouters, F., Villarreal, L. Y. B., Jerez, J. A., \& Costa, G. M. (2009). Surto de diarreia em vacas de um rebanho leiteiro na região sul de Minas Gerais: Detecção de coronavírus bovino nas fezes. Arquivo Brasileiro de Medicina Veterinaria e Zootecnia, 61(4), 992-995. DOI: https://doi.org/10.1590/s0102-09352009000400030

Bok, M., Alassia, M., Frank, F., Vega, C. G., Wigdorovitz, A., \& Parreño, V. (2018). Passive immunity to control Bovine coronavirus diarrhea in a dairy herd in Argentina. Revista Argentina de Microbiologia, 50(1), 23-30. DOI: https://doi.org/10.1016/j.ram.2017.03.007

Brandão, P. E. ., Gregori, F. ., Sforsin, A. J. ., Villarreal, L. Y. B. ., \& Jerez, J. A. . (2007). Winter dysentery in cows associated with Bovine. Arquivo Brasileira de Medicina Veterinaria e Zootecnia, 99(4), 1074-1076. DOI: https://doi.org/10.1590/s0102-09352007000400038

Dash, A. S. K., Kumar, K., Goel, A., \& Bhatia, A. K. (2012). Detecção do antígeno do vírus corona por ELISA em bezerros diarréicos de vaca em. Mundo Veterinário, 5(3), 6-9.

FAPRI. (2020). Food and Agricultural Policy Research Institute (W. A. O. Database (ed.)). Food and Agricultural Policy Research Institute; Iowa State University and University of Missouri-Columbia. http://www.fapri.iastate.edu/tools/outlook.aspx

Fehr, A. R., \& Perlman, S. (2015). Coronaviruses: an overview of their replication and pathogenesis. Coronaviruses, 1-23. DOI: https://doi.org/10.1007/978-1-4939-2438-7_1

Floss, B. D., Martins, R. K., \& Sperotto, V. R. (2019). Diarreia neonatal bovina: revisão de literatura. Revista Interdisciplinar de Ensino. Pesquisa e Extensão, 7, 62-71.

Fulton, R. W., Herd, H. R., Sorensen, N. J., Confer, A. W., Ritchey, J. W., Ridpath, J. F., \& Burge, L. J. (2015). Enteric disease in postweaned beef calves associated with Bovine coronavirus clade 2. Journal of Veterinary Diagnostic Investigation, 27(1), 97-101. DOI: https://doi.org/10.1177/1040638714559026

Geng, J.-J., Gong, Z., Li, Q., Shen, X., \& Wei, S. (2019). Specific Detection of Bovine Coronavirus N Protein with TaqMan Probe qRT-PCR. Acta Scientiae Veterinariae, 47(1), 1-8. DOI: https://doi.org/10.22456/1679-9216.97156

Gomez, D. E., Arroyo, L. G., Poljak, Z., Viel, L., \& Weese, J. S. (2017). Detection of Bovine Coronavirus in Healthy and Diarrheic Dairy Calves. Journal of Veterinary Internal Medicine, 31(6), 1884-1891. DOI: https://doi.org/10.1111/jvim.14811

Headley, S. A., Balbo, L. C., Alfieri, A. F., Saut, J. P. E., Baptista, A. L., \& Alfieri, A. A. (2017). Bovine respiratory associated with Histophilus somni and bovine respiratory syncytial virus in a beef cattle feedlot from Southeastern Brazil. Semina:Ciencias Agrarias, 38(1), 283-293. DOI: https://doi.org/10.5433/1679-0359.2017v38n1p283

Jerez, J. A., Brandão, P. E., Buzinaro, M. G., Gregori, F., Rosales, C. A. R., Ito, F. H., \& Sakai, T. (2002). Detecção de rotavírus e coronavírus em fezes de bezerros neonatos com diarréia criados em vários municípios do Estado de São Paulo, Brasil. Instituto de Biologia, 69(2), 19-23.

Júnior, S. F. V. (2015). Diarreia em bezerros na região sul do Rio Grande do Sul. Universidade Federal de Pelotas, 42.

Kanno, T., Kamiyoshi, T., Ishihara, R., Hatama, S., \& Uchida, I. (2018). A long-term animal experiment indicating persistent infection of bovine coronavirus in cattle. The Journal of Veterinary Medical Science, 17. DOI: https://doi.org/10.1292/jvms.18-0050

Letko, M., Marzi, A., \& Munster, V. (2020). Functional assessment of cell entry and receptor usage for SARS-CoV-2 and other lineage B betacoronaviruses. Nature Microbiology, 5(4), 562-569. DOI: https://doi.org/10.1038/s41564-020-0688-y

Lorenzetti, E., Leme, R. de A., Ribeiro, J., Souza, V. R. A. de, Alfieri, A. F., \& Alfieri, A. A. (2013). Neonatal diarrhea by bovine coronavirus $(\mathrm{BCoV})$ in beef cattle herds. Semina:Ciencias Agrarias, 34(2), 3795-3800. DOI: https://doi.org/10.5433/1679-0359.2013v34n6supl2p3795

Mello, Janaina Lustosa De. (2018). Isolamento, Caracterização molecular e análise filogenética do gene da glicoproteína $\mathrm{S}$ de coronavírus bovino associado à doença respiratória. In Universidade Federal do Paraná. Universidade Federal do Paraná. 
Mello, J. L;, Lorencena, D. ., Delai, R. R., Kunz, A. F.Possati, F., \& Takiuchi, E. (2016). Detecção do coronavírus bovino em bezerros com doença respitatória no município de ouro verde do oesteParaná. Copesah, 174-176.

Oliveira, K. D. R. de. (2018). Caracterização dos diferentes tipos de diarreia neonatal em bezerros: revisão de literatura. In Cesmac. Centro Universitário Cesmac.

Pavarini, S. P. (2009). Achados clínicos e patológicos em casos naturais e experimentais de desinteria de inverno em bovinos adultos [Universidade Federal do rio grande do sul]. In Universidade federeal do Rio Grande do Sul (Vol. 1, Issue 9). https://doi.org/10.1017/CBO9781107415324.004

Radostits, O. M., Gay, C. C., Blood, D. C., Hinchcliff, K. W., \& McKenzie, R. A. (2010). Clínica Veterinária: um tratado de doenças dos bovinos, ovinos, suínos, caprinos e eqüinos (Vol. 1). Guanabara Koogan.

Reck, M. V. M. (2009). Diarréia neonatal bovina [Universidade Federal do Rio Grande do Sul]. In Universidade Federal Do Rio Grande Do Sul. https://doi.org/10.1037/0003-066X.55.1.34

Saif, L. J. (2010). Bovine respiratory coronavirus. Veterinary Clinics of North America - Food Animal Practice, 26(2), 349-364. https://doi.org/10.1016/j.cvfa.2010.04.005

Serafini, M. F. (2016). Estudo do complexo de doenças respiratórias dos bovinos em confinamento de terminação: Fatores de risco, Aspectos Clínicos e Anatomopatológicos. Universidade Federal de Minas Gerais. https://doi.org/10.1017/CBO9781107415324.004

Silva, D. G., Montassier, H. J., Oloiveira, R. G., Fuentes, D. B., Samara, S. I., Jerez, J. A. \& Buzinaro, M.G. (2008) Avaliação da imunidade passiva em bezerros nascidos de vacas imunizadas com vacina contra rotavírus. Arquivo Brasileiro de Medicina Veterinária e Zootecnia. 60, (5), 1089-1096. http://dx.doi.org/10.1590/S0102-09352008000500008

Sonza, S. (2006). Disenteria de Inverno : Detecção de coronavírus bovino ( $\mathrm{BCoV}$ ) por reação de PCR dirigida ao gene Rp Rd e isolamento em cultivo celular de HRT-18G. Universidade de São Paulo.

Souza, S. P., Asano, K. M., Buitrago, L. Y. V., Silva, S. de O. S., Richtzenhain, L. J., \& Brandão, P. E. (2010). A semi-nested RT-PCR assay targeted to hemagglutininesterase gene of Bovine Coronavirus. Brazilian Journal of Veterinary Research and Animal Science, 47(4), 323-328. https://doi.org/10.11606/issn.1678-4456.bjvras.2010.26832

Souza, S. P. (2008). Epidemiologia molecular em um surto de disenteria de inverno em bovinos leiteiros adultos no Estado de São Paulo e descrição de genótipos para o Coronavírus bovino (BCoV).

Souza, V.F., Soares, C.O. \& Ferreira, S.F. (2009) Vacinação, a importância das boas práticas e a prevenção de doenças de interesse em bovinocultura. Comunicado Técnico 122. EMBRAPA

Szczepanski, A., Owczarek, K., Bzowska, M., Gula, K., Drebot, I., Ochman, M., Maksym, B., Rajfur, Z., Mitchell, J. A., \& Pyrc, K. (2019). Canine Respiratory Coronavirus, Bovine Coronavirus, and Human Coronavirus OC43: Receptors and Attachment Factors. MDPI, 23. DOI: https://doi.org/10.3390/v11040328

Takiuchi, E., Antônio, M., Barreiros, B., Alfieri, A. F., \& Alfieri, A. A. (2007). Identification of a mutation in the spike protein cleavage site in brazilian strains of wild-type bovine coronavirus. Brazilian Journal of Microbiology, 699-703. DOI: https://doi.org/10.1590/s151783822007000400021

Yavru, S., Yapici, O., Kale, M., Sahinduran, S., Pehlivanoglu, F., Albay, M. K., \& Avci, O. (2016). Bovine Coronavirus (BoCV) Infection in Calves with Diarrhoea and Their Dams. Acta Scientiae Veterinariae, 44(1), 7. DOI: https://doi.org/10.22456/1679-9216.81176

Histórico do artigo:

Recebido: 27 de novembro de 2020. Aprovado: 19 de janeiro de 2021.
Licenciamento: Este artigo é publicado na modalidade Acesso Aberto sob a licença Creative Commons Atribuição 4.0 (CC-BY 4.0), a qual permite uso irrestrito, distribuição, reprodução em qualquer meio, desde que o autor e a fonte sejam devidamente creditados. 